\title{
On a New Approach for Determining the Balance of Male Trousers
}

\author{
Manuela Avadanei \\ Faculty of Textiles, Leather and Industrial Management \\ "Gheorghe Asachi" Technical University \\ Iasi, Romania
}

\author{
Emilia Filipescu \\ Faculty of Textiles, Leather and Industrial Management \\ "Gheorghe Asachi" Technical University \\ Iasi, Romania
}

\begin{abstract}
Nowadays, personalized and individualized products with high-quality characteristics are demanded by all consumers. Among these products, the garments are the ones which accurately reflect the fashion trendlines, the diversified consumer tastes, needs, level of education, and financial resources. Like any other personalized/individualized goods, they must be comfortable, have to put the wearer's features in a positive light, and they must also fit into fashion trendline. Comfort is a complex feature of a garment which must be considered from the design stage (all the elements/pieces are designed), up until the production process (the pieces are processed according to the complexity of the model, materials, type of equipment), in order to enable it to withstand the usage of the product (consumer use). The dimensional correspondence between the human body and the garments plays an essential role in ensuring the wearing comfort of clothes. The human body (posture, conformation and proportions) and the fashion trendlines determine the shape and size of the garment pieces. The design process of the garment pieces starts with the analysis of the model, properties of the material, and of the manufacturing technology. This paper presents a new approach in designing the patterns of personalized/ individualized products, male trousers, by taking into consideration the anthropometric indicators which characterise the posture of the human body.
\end{abstract}

Keywords: Constructive balance, garment quality, dimensional correspondence.

\section{INTRODUCTION}

Various types of IT solutions are used in each branch of industry because they offer higher precision, require less effort and time for each stage of the production process, they minimize the production costs, offer multiple solutions for different problems, and optimize the whole production process, enabling the designers to focus on finding flexible and more creative solutions. The users (designers) can explore multiple solutions for the same issue, compare them (identify advantages or disadvantages) and finally decide which one is the best.

It is a known fact that any consumer is looking for goods which satisfy all of her/his personal needs, with a high level of quality and at an affordable price. On the other way, the industry is a highly competitive business environment, in which producers who are manufacturing the same type of products always have to come with the best ideas if they wish to survive as an enterprise. This is the same in the case of clothing manufacturers. Unlike the manufacturers that produce standard goods, they must make certain changes in the approach of the design process of the new product (garment), in order to be able to produce personalized/individualized garments, in a wide range of models and sizes.

Quality is a characteristic of a clothing product that must be permanently considered during the design and production stages and it is constantly tested during the usage of the product. The quality of a garment has multiple features: the manner in which the product obeys the fashion trends, its manufacturing method, composition (the balance between the model and the type of materials from which it is produced), and last but not least, the correspondence between the garment and the wearer. The latter refers to the extent to which the product is harmonized with the wearer's physiognomy and to the way in which it fits his/her body shape (posture, conformation and proportions).

For garments supported on the waist (such as trousers), the support area is defined by the circumference of the waist, hips circumference, the anterior, the lateral and posterior surface between waist and hips. On these areas, the garment must fit very well, whereas below this area the garment may be very loose or not. The trousers balance is defined by its appearance: the position of the hemline and of the outside and inside longitudinal seams. If the hemline is parallel with the floor, and if the inside and outside longitudinal seams are perpendicular on the hemline and at the same time on the floor, then it can be said that the trousers are well balanced on the human body.

In the design process of the trousers the following aspects must be considered:

-this garment covers the pelvis and the lower limbs, which are body parts that are very different from a person to another (shape and dimensions)

-these parts of the body have a great degree of mobility, which must not be hindered while the trousers are being worn;

-fashion trends determine changes in the silhouette, in the position of the waistline (the waistline may have a normal position, high or very high position, low or very low position), if the model is equipped with a waistband or zipper (and whether the latter is placed on the middle line of the front or back, or on the lateral side) and if it has pockets or any other decorative elements.

In general, three categories of information are necessary in the design process of the trousers patterns: human body perimeters (waist and hips perimeters), trousers dimensions (inside and /or outside longitudinal lengths, sometimes trousers widths at the level of the waistband or of the hips line), and allowances (on the waist and hips).

This paper proposes a new approach to the design process of the trousers (individualized/personalized) by taking into consideration: 
- anthropometric indicators which characterize the pelvis area and the position of the lower limbs;

-constructive indicators which evaluate the position of the trousers on the human body (for the static or dynamic position).

\section{WORK METHOD}

In order to elaborate this new solution it was necessary to analyze several constructive solutions (8) which are used by different designers to make male trousers patterns: 1- Poland [7], 2- Germany [8]; 3- England [1]; 4- Germany [3]; 5Russia [2]; 6- Germany [6]; 7- CAER [9]; 8- Poland [5].

The patterns are made for several sizes in each of the aforementioned solutions, and they are analyzed (compared) afterwards, by considering the following aspects:

a) the number and types of anthropometric dimensions which are used for dimensioning the patterns;

b) the number and types of the garment dimensions which are used in each method;

c) the types of all the necessary allowances, which determine the functionality, appearance and silhouette of the product;

d) the sequences of the designing process;

e) the complexity and the structure of the mathematical relations used for determining the value of the constructive segments.

In general, all the authors of the chosen solutions use mathematical relations, which have the following general structure (linear regression):

$$
\mathrm{Y}=\mathrm{b}_{0}+\mathrm{b}_{1} \mathrm{x}_{1}+\mathrm{b}_{2} \mathrm{X}_{2}+\ldots .+\mathrm{b}_{\mathrm{n}} \mathrm{x}_{\mathrm{n}}
$$

Where:

$\mathrm{Y}$ is the constructive segment of the pattern;

$\mathrm{x}_{1}, \mathrm{x}_{2}, \ldots, \mathrm{x}_{\mathrm{n}}$ are the anthropometric parameters;

$b_{0}, b_{1}, \ldots b_{n}$ are the correlation coefficients which express the correlation between the initial anthropometric data used for calculating the value of the constructive segments and the corresponding value of the body dimension of the constructive segment.

After the patterns were drawn, they were compared and some differences were noticed between them (for the same size). For the purpose of this paper, the values of the constructive segments placed on the support area were taken into consideration. The experimental data were analyzed by using statistical methods.

Figure 1 shows the constructive parameters that have been chosen for the purpose of this paper, whereas table 1 presents the definition and symbol for each one.
TABLE I. Constructive parameters

\begin{tabular}{|l|l|l|l|}
\hline No. & $\begin{array}{l}\text { The significance of constructive } \\
\text { parameter }\end{array}$ & Symbol & Fig. \\
\hline 1. & $\begin{array}{l}\text { The step height; the distance } \\
\text { between the waist and the fly line }\end{array}$ & $\mathrm{D}_{\mathrm{W}-\mathrm{fly}}$ & $\mathrm{a}$ \\
\hline 2. & $\begin{array}{l}\text { The distance between the waist and } \\
\text { the hip line }\end{array}$ & $\mathrm{D}_{\mathrm{W}-\mathrm{hip}}$ & $\mathrm{b}$ \\
\hline 3. & $\begin{array}{l}\text { The distance between the fly line } \\
\text { and the knee line }\end{array}$ & $\mathrm{D}_{\mathrm{fly}-\mathrm{knee}}$ & $\mathrm{c}$ \\
\hline 4. & The width of the fly cut & $\mathrm{l}_{\mathrm{rs}}$ & $\mathrm{d}$ \\
\hline 5. & The width of the back cut & $1_{\mathrm{rs}}$ & $\mathrm{e}$ \\
\hline 6. & The front width on the hip line & $1_{\mathrm{fS}}$ & $\mathrm{f}$ \\
\hline 7. & The back width on the hip line & $1_{\mathrm{sS}}$ & $\mathrm{g}$ \\
\hline 8. & The front width on the waistline & $1_{\mathrm{ft}}$ & $\mathrm{h}$ \\
\hline 9. & The back width on the waistline & $1_{\mathrm{st}}$ & $\mathrm{i}$ \\
\hline 10. & The posterior constructive balance & $\mathrm{e}_{\mathrm{p}}$ & $\mathrm{j}$ \\
\hline 11. & The anterior constructive balance & $\mathrm{e}_{\mathrm{a}}$ & $\mathrm{k}$ \\
\hline
\end{tabular}

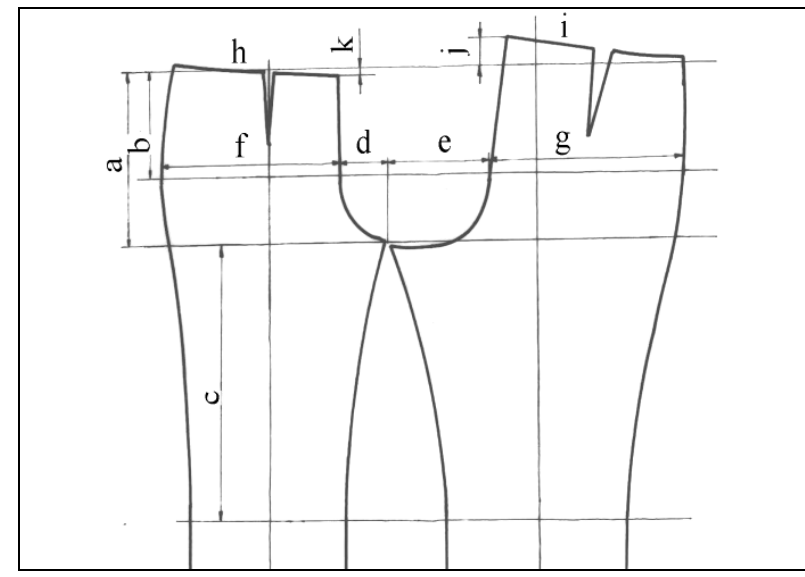

Fig. 1. Constructive parameters

\section{DETERMINING THE CONSTRUCTIVE BALANCE OF THE "MALE TROUSERS"}

The constructive balance $\left(\mathbf{e}_{\mathbf{c}}\right)$ of the male trousers refers to two aspects:

the anterior balance which is expressed by the position of the waistline on the front part of the pattern, with respect to the waistline of the base pattern (fig. 1)

the posterior balance ( $\left.\mathbf{e}_{\mathbf{p}}\right)$ evaluated by taking into account the position of the highest point of the backside, with respect to the waistline of the pattern (fig. 1).

The results show that most of the authors consider the posterior balance $\left(\mathbf{e}_{\mathbf{p}}\right)$ to be the essential constructive parameter. This parameter has the greatest degree of variability.

All the specialists in the field of clothing design have shown that when the product size is altered, the waistline of the front pattern must change its position in order to obtain a good balance and fitting degree of the garment on the human body [4].

In order to use the constructive balance $\left(\mathbf{e}_{\mathbf{c}}\right)$ in the design process of the patterns of individualized/personalized male trousers, it is necessary to determine the anterior and posterior constructive balance (e $\mathbf{e}_{\mathbf{a}}$ and $\left.\mathbf{e}_{\mathbf{p}}\right)$.

It is known from the literature that the posterior balance is usually determined by knowing the values of two 
anthropometric dimensions which characterize the shape and size of the pelvis area: half of the waist perimeter $\left(\mathrm{p}_{\mathrm{t}}\right)$ and half of the hip perimeter $\left(\mathrm{p}_{\mathrm{s}}\right)$. This parameter is calculated as follows:

$\mathrm{e}_{\mathrm{p}}=\frac{\mathrm{p}_{\mathrm{s}}-\mathrm{p}_{\mathrm{t}}}{2}$

By analyzing the values of this constructive parameter, which was measured on trousers patterns for various sizes, one can notice that there is a linear dependence between it and the sizes of the trousers (as it is shown in fig.2).

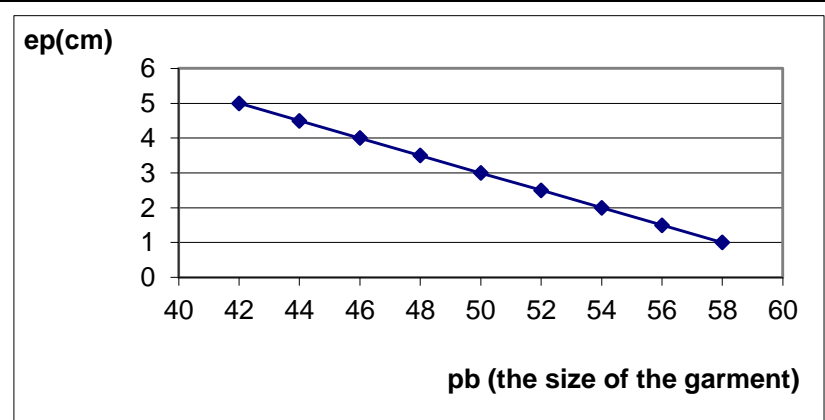

Fig. 2. The dependence between the size of the male trousers and the posterior the balance of the pattern (the size of the garment is represented by a half of the bust perimeter)

This type of dependence led the authors of this paper to analyze the connection between this constructive parameter and $\mathbf{p}_{\mathbf{t}}$ and $\mathbf{p}_{\mathbf{s}}$, for all of the selected sizes.

Table 2 shows the values for $\mathbf{p}_{\mathbf{t}}, \mathbf{p}_{\mathbf{s}}$ and $\mathbf{p}_{\mathbf{b}}$ (calculated with the corresponding perimeters from the Anthropometric Standard [10]) along with the values of $\mathbf{e}_{\mathbf{p}}$ and $\mathbf{e}_{\mathbf{a}}$, which are constructive parameters.

TABLE II. Values for $\mathrm{p}_{t}, \mathrm{p}_{\mathrm{s}}$ and $\mathrm{p}_{\mathrm{b}}$

\begin{tabular}{|l|l|l|l|l|l|l|l|l|l|}
\hline $\begin{array}{l}\text { Size } \\
\mathbf{p}_{\mathrm{b}}=\mathbf{P}_{\mathrm{b}} / \mathbf{2}\end{array}$ & $\mathbf{4 2}$ & $\mathbf{4 4}$ & $\mathbf{4 6}$ & $\mathbf{4 8}$ & $\mathbf{5 0}$ & $\mathbf{5 2}$ & $\mathbf{5 4}$ & $\mathbf{5 6}$ & $\mathbf{5 8}$ \\
\hline $\mathrm{p}_{\mathrm{s}}=\mathrm{P}_{\mathrm{s}} / 2$ & 45.5 & 47.5 & 49.5 & 51.5 & 53.5 & 55.5 & 57.5 & 59.5 & 61.5 \\
\hline $\mathrm{p}_{\mathrm{t}}=\mathrm{P}_{\mathrm{t}} / 2$ & 35.5 & 38.5 & 41.5 & 44.5 & 47.5 & 50.5 & 53.5 & 56.5 & 59.5 \\
\hline $\mathrm{p}_{\mathrm{s}}-\mathrm{p}_{\mathrm{t}}$ & 10 & 9 & 8 & 7 & 6 & 5 & 4 & 3 & 2 \\
\hline $\begin{array}{l}\mathrm{e}_{\mathrm{p}}= \\
\left(\mathrm{p}_{\mathrm{s}}-\mathrm{p}_{\mathrm{t}}\right) / 2\end{array}$ & 5 & 4.5 & 4 & 3.5 & 3 & 2.5 & 2 & 1.5 & 1 \\
\hline $\mathrm{e}_{\mathrm{a}}=\mathrm{f}\left(\mathrm{p}_{\mathrm{b}}\right)$ & 2 & 1.5 & 1 & 0.5 & 0 & -0.5 & -1 & -1.5 & -2 \\
\hline
\end{tabular}

By analyzing the values from table 2 (for different sizes), one can infer that there is a linear dependence between $\mathbf{p}_{\mathbf{b}}$ and $\mathbf{e}_{\mathbf{p}}$, and $\mathbf{p}_{\mathbf{b}}$ and $\mathbf{e}_{\mathbf{a}}$, respectively, which has the general mathematical expression

$$
\mathrm{Y}=\mathrm{k} \cdot \mathrm{x}+\mathrm{b} \text {, where: }
$$

Identify applicable sponsor/s here. If no sponsors, delete this text box (sponsors)
$\mathrm{Y}$ is the dependent variable $\left(\mathrm{e}_{\mathrm{p}}\right.$ respectively $\mathrm{e}_{\mathrm{a}}$ );

$\mathrm{k}, \mathrm{b}$ are the coefficients of the equation (regression);

$\mathrm{x}$ is the independent variable $\left(\mathrm{p}_{\mathrm{b}}\right)$.

The values of the coefficients are determined by solving the following linear system of equations:

$$
\left\{\begin{array}{l}
5=\mathrm{k} \cdot 42+\mathrm{b} \\
1=\mathrm{k} \cdot 58+\mathrm{b}
\end{array}\right.
$$

By solving this system, one finds that $\mathrm{k}=-0.25$.

By replacing this value in one of the previous relations, one can infer that $b=15.5$ and the general expression for $\mathbf{e}_{\mathbf{p}}$ becomes:

$$
e_{p}=-0.25 p_{b}+15.5
$$

For size 50, which is considered to be a medium size for the normal conformation group, the waistline has a horizontal position for the front side and the value for the parameter $b_{1}$ is determined from the general equation for $e_{a}$ :

$$
\mathrm{b}_{1}=\mathrm{b}-3=12.5
$$

On these terms, the mathematical relation describing $\mathbf{e}_{\mathbf{a}}$ becomes :

$$
e_{a}=-0.25 \cdot p_{b}+12.5
$$

Fig. 3 shows the positions of the waistline (front and back) after calculating the values of $\mathrm{e}_{\mathrm{a}}$ and $\mathrm{e}_{\mathrm{p}}$ (sizes 48, 50 and 52).

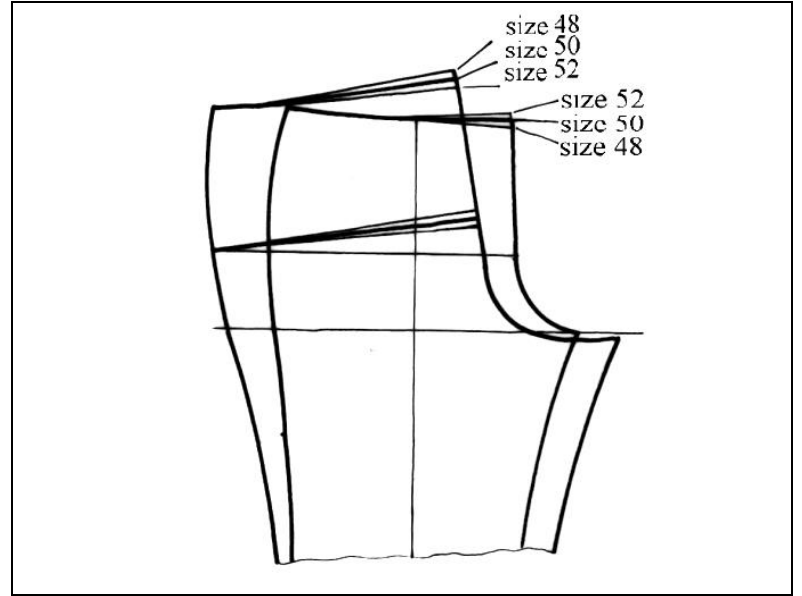

Fig. 3. The waistline positions (front and back) in concordance with the anterior-posterior balance

\section{EXPERIMENTAL RESULTS}

The analysis of the values of the main constructive parameters (table 1) of the trousers patterns, which were designed by using eight different solutions, underlines the existence of some differences among the selected solutions for drawing patterns. These differences are 
determined by the methods used for constructing the patterns and the structure of the initial data.

The variability degree of the constructive parameters values was analyzed by using statistical methods (by determining the value of the variation coefficient, see fig. 4).

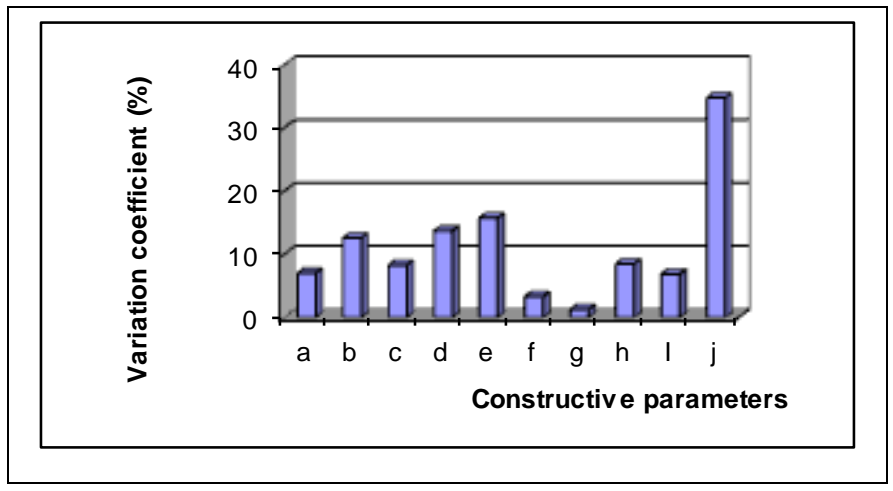

Fig. 4. The graphic of the variation coefficient

By analyzing the graphic from fig. 4, one can notice that:

- The six constructive parameters are characterized by a high degree of homogeneity and they define the cut line and the trousers silhouette;

- A medium variability is registered in the case of the segments that establish the position of thefly and the backside cut line;

- The biggest variability is registered with respect to the method by which the balance is evaluated.

All the results underline the idea that in the trousers design sequence it is compulsory to use a constructive parameter, namely balance, which is determined in the manner that has been described in this paper.

\section{CONCLUSIONS}

This study led to the following conclusions:

-this comparative analysis of different constructive solutions for male trousers underlines the absence of primary data, useful in determining $\mathrm{e}_{\mathrm{a}}$ and $\mathrm{e}_{\mathrm{p}}$;

-all of the mathematical relations proposed to determine $e_{a}$ and $e_{p}$ are simple, because all of them are linear and depend only on pb. This quantity, expressed as $\mathrm{Pb} / 2$ is very easy to determine due to the fact that the bust perimeter can be easily measured with a high degree of accuracy; -if one considers " $\mathbf{e}_{\mathbf{a}}$ and $\mathbf{e}_{\mathbf{p}}$ " (calculated in correlation with the trousers size) during the design process, the front and the back waistline will have a good position, which in turn means a good dimensional correspondence between the garment and the human body on the support area (comfort during usage, as well as a good appearance of the product);

-in general, the values for ea are positive or negative, with the exception of size 50 (normal conformation group), when $\mathbf{e}_{\mathbf{a}}=\mathbf{0}$. When $\mathrm{e}_{\mathrm{a}}$ takes poitive values, the position of the waistline will be lower than in the case of the medium size. When $\mathrm{e}_{\mathrm{a}}$ takes negative values, the position of the waistline will be higher than in the case of the medium size;

-the values for the posterior balance decrease as the garment size grows.

The consideration of the $\mathbf{e}_{\mathbf{a}}$ and $\mathbf{e}_{\mathbf{p}}$ constructive parameters during the whole design process of the male trousers will determine a good fit and appearance of the trousers on the human body. These constructive parameters can be easily determined for each customer. By introducing them in the design scenario, the designer will be able to make a good pattern from the beginning, and this will reduce the number of needed samples and adjustments, as well as the time and costs necessary to obtain a product that is properly and comfortably fitted on the human body.

\section{REFERENCES}

[1] Aldrich W. "Metric pattern cutting for menswear", London, 1997

[2] Grișpan I.Ia."Samouciteli raskroia mujskih i jenskih briuk i jiletov", Rifmopoligraf, Moskova, 1992

[3] Jansen J. "Systemschintt", vol. I, Berlin, 1994

[4] Kirakosian V.K. "Konstruirovanie mujskoi verhnei odejdî s ispolizovaniem EVM", Legkaia i pişcevaia promîşlennosti, Moskova, 1982

[5] Kula W. "Spodnie mlodziezowe", Modne krawiectwo, nr. 1, 1986, Warszawa

[6] Nattkemper A. "Die Anzughose", Bekleidung Wasche, nr 18,1981

[7] Piskorska M., Parafianovich Z., Smolen M. "Funkcjonalnosc i estetyka spodni meskichdva vykluczajace sie czynnikiz", Odziez, nr.6, 1980

[8] *** Rundschau, nr.1-2, 1996

[9] *** "Edinaia metodika konstruirovania odejdî SEV (EMKO SEV). Bazovîe konstrukţii mujskoi odejdî", tom 3 Moskova, 1988

[10] *** SR 13544. Îmbrăcăminte. Dimensiunile corpurilor şi mărimi de confecţii pentru bărbaţi 